Article

\title{
Organisational Welfare in Italian SMEs: The Process of Valorising Human Resources
}

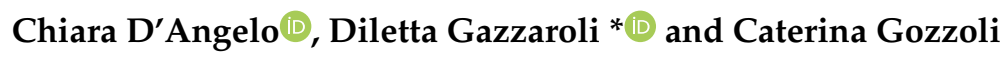 \\ Faculty of Psychology, Università Cattolica del Sacro Cuore, 20123 Milano, Italy; \\ chiara.dangelo@unicatt.it (C.D.); caterina.gozzoli@unicatt.it (C.G.) \\ * Correspondence: diletta.gazzaroli@unicatt.it
}

Received: 15 October 2020; Accepted: 5 November 2020; Published: 10 November 2020

\begin{abstract}
Organisational welfare is a complex private system that offers advantages to a company and its employees. However, when occupational welfare is largely implemented as an "economic" strategy, there is a high probability that it would not necessarily be capable of guaranteeing a profit. The risks and possibilities associated with the implementation of a welfare programme incur further challenges if applied to the context of SMEs. Thus, SMEs are organisational realities characterised by specific emotional and relational dynamics. As such, welfare in these realities takes on deep value and significance and so it potentially impacts processes of valorising human resources. With our study, we analysed welfare practices and representations within specific organisational realities (SMEs) in order to understand how welfare could impact organisational processes of valorising human resources. Based on our results, we realised that welfare can be seen as a sort of magnifying glass that allowed for the detection of the themes that led the organisations to reflect on their rooted values and identities. We suggest that SMEs should think about welfare as a process rather than a product, strengthening their awareness of factors, dynamics and processes that define the complexity of the quality of life in organisations.
\end{abstract}

Keywords: organisational welfare; employee welfare; quality of life; SMEs; organisational processes

\section{Introduction}

Nowadays, as well as compared to relatively recently, it can be said that the quality of organisational life and care in human resources are widely debated topics, not only in academia but also, and especially, within companies' parameters [1,2].

An emblematic example of this is organisational welfare. On a general common-sense level, we can obtain a certain degree of agreement on the definition of organisational welfare as an umbrella concept that comprises different services and benefits offered by an organisation to its employees; we can also agree on the importance that this holds [2-4].

It is legitimate to ask whether this interest is the result of conforming to a trend or if it is grounded in an organisational vision of human resources, in terms of human capital in whom to invest in for a return of productivity and competitiveness [5-7].

Within this debate, this paper aims to analyse welfare practices and representations within specific organisational realities (SMEs) in order to understand how welfare could be impacting on the organisational processes of valorising human resources.

\subsection{Organisational Welfare: Lights and Shadows of a Complex Topic}

Organisational welfare is recognised as a "complex private system ( ... ) that, limited to workers in a certain company and their families, impacts the same needs that are satisfied by the mandatory public welfare system, or that preserves and safeguards other needs with additional and different 
services compared to public ones" [8] (p. 103). This type of private welfare, also called second level welfare, has recently seen new development for various reasons. The first reason is linked to the range of services guaranteed by the national welfare system and, in particular, to issues of financial sustainability in the health and social security system [8-10]. The second can be linked to the alteration of socio-economic circumstances and new welfare needs determined by the ageing of the population, by the "nuclearization" of families and by the increase of female participation in the professional world [8,9]. Finally, another element that contributed to the re-emergence of organisational welfare is the affirmation of the idea that organisational welfare politics are represented as mechanisms to incentivise and increase employees' loyalty, aimed at reaching better performance [1,2,9-13].

We certainly find ourselves in a historic time in which organisational welfare, in addition to offering an economic advantage to the company and the employee, also has a protective function against social risks - especially in nations where the State has progressively reduced its involvement in social politics. In other words, organisational welfare measures produce positive externalities as they bring advantages not only to employees, but to their families and wider community.

In addition to this, organisational welfare measures offer companies an advantage in terms of their image, reputation and trust; organisational welfare can be seen as a tool for the implementation of a company's social responsibilities [14-16].

However, there are a number of critical elements in the Italian context that are worth paying attention to.

The first one concerns performance bonuses that, per employees' choices, can be received in the form of welfare not subject to tax. For this reason, one of the possible objections to organisational welfare is that it is carried out with employees' money [10].

Another issue linked to the performance bonus being received as private welfare concerns the risk of inequality between workers. In fact, when the award mechanism uses contractual levels as a criterion (as opposed to employees' needs), the welfare amplifies, instead of offsets, the differences in remuneration as people with lower remuneration (that could therefore struggle to set aside part of their salary for private welfare needs) also find themselves receiving a smaller share of organisational welfare. Another matter also related to this argument is the change in the demanded work "quality" [8-17]. On the one hand, there is the increase in the demand for creative professionals, with social skills that are responsible and proactive; these workers tend to ask for more innovative and personalised services. On the other hand, however, in our country there is still a large portion of less specialised workers (usually blue collars) who prefer to receive money in their wages instead of benefits and services. Therefore, our country is characterised by an employment structure that is quite "polarized", thus accentuating economic and social inequalities.

In light of these challenges, it seems appropriate to state that if occupational welfare is to be mainly implemented as an "economic" strategy, there is a high probability that the result will be its minimisation to a simple administration practice, a commodity that would not necessarily be capable of guaranteeing a return in terms of profit.

To avoid these risks during the implementation of a welfare programme, the literature highlights the importance of paying attention to certain process elements.

This means, firstly, to pay particular attention to the welfare planning. Thus, needs should not be identified a priori and instead only from upper management. Spending time and attention on the analysis and understanding of people's needs and on the definition of company objectives is fundamental to trace the line set out in the design [10]. Indeed, to support the welfare implementation process, it is preferable to start from the inclusion of the beneficiaries themselves [2,8,18]. Once the plan has been designed on the basis of the needs analysis, in addition to having transparent communication surrounding it, it is essential to activate monitoring and evaluation actions.

To support this type of approach, in addition to converting performance bonuses, organisations can choose to provide unilateral welfare. In other words, the company offers forms of welfare not because they are tied to contractual obligations but as a voluntary and contextualised decision. 
This formula is considered to be particularly appealing, not just because from a fiscal and contributory point of view it is equivalent to the contractual one (as services are not subjected to taxes and contributions), but because it leaves freedom of action to companies and facilitates a direct relationship without any sort of mediation between the company and its employees [10].

That is, we can state that all the suggestions for a successful implementation of welfare proposals, presuppose the centrality and enhancement of human resources and their well-being $[6,19]$.

\subsection{Organisational Welfare in $S M E s$}

The reflections reported thus far regarding the opportunities, risks and possibilities that a welfare programme implementation have for a company, incur further challenges if applied to the context of SMEs [12]. SMEs are in fact characterised by several specific challenges related to the enhancement of human resources and social capital.

Assuming the notion that organizations make choices depending on the reference point of their dominant principals, for SMEs, where emotional ties and affective bondings are inextricably intertwined with organisational history, a key factor is to encourage increasing levels of consonance and intersystemic resonance, to always preserve and enhance the advantages of flexibility and adaptability, therefore overcoming the limits of their smaller size and limited financial, human and technological resources [20-25].

Other than receiving indications on the style of communication and on the welfare formula to implement, to find a real answer to issues that SMEs raise in regards to an efficient implementation of the welfare system, it is necessary to interrogate ourselves on a deeper organisational level, as concerning its deeper "human" connotation the meaning that this can carry is significantly more blurred. In fact, as demonstrated in previous papers [2,13,26,27], organisational welfare guarantees a return when it is perceived as an integral factor of the quality of organisational life, and when it is coherent to an organisational culture that pays attention to investing in order to take care of its human resources. In other words, there is an implied need to abandon the welfare logic to leave room for a vision of capitalisation of the value of human resources.

That is, as suggested by Ko \& Choi [28] if SME employees experience act of caring in response to the suffering of others, they would feel authenticity and form positive emotions with other employees and thereby make a stronger affective commitment to the organization itself.

For SMEs, the crucial aspect then becomes "how" organisational welfare is depicted, designed and achieved. It is in this process itself that organisational welfare can be defined as a top down policy (that is ineffective in terms of returns) or as the manifesting of an organisational culture that chooses to dedicate time and attention to the understanding of human resources (and is efficient in terms of returns).

Due to the limited number and "proximity" between top management and human resources, SMEs are organisational realities characterised by specific emotional and relational dynamics [23,28]. Thus, the mutual bond is stronger and more personal. For these reasons, welfare in these realities takes on an exceedingly deep value and significance and so it potentially impacts the processes of valorising human resources. However, in literature, the tendency is to look at "what" is done in terms of welfare proposals and the analysis of "how" is limited to the design phases and is not declined as an outcome in terms of experiences and relational impact in human resources. With our work we intend to explore these aspects starting from SMEs as they represent a really widespread and particular organizational context in terms of human resources management.

\section{Materials and Methods}

\subsection{Aims and Scope}

This research has three main goals. The first is to outline a welfare proposal map in a number of SMEs. The second is to explore representations related to organisational welfare, the meaning linked to 
the topic. Finally, the third is to delineate different elements about the process of welfare programme implementations in SMEs.

\subsection{Sample}

Thanks to close collaboration with a trade union, it was possible to get in touch with 10 SMEs. Specifically, the sampling was designed in reference to the SMEs of Brescia for their high concentration in this Lombard territory.

An initial inclusion criterion was the number of employees. The companies to be included had to have, regardless of revenue and profit, a minimum of 20 and a maximum of 150 employees. We decided to establish these cut-off points because these ranges of numbers favour the creation of relational bonds and emotional closeness and, therefore, in these kinds of enterprises the choice of welfare becomes a crucial organisational investment in symbolic terms. Different sectorial categories were also included. We chose to include 10 different categories as the focus was on SMEs and the dynamics that characterize them regardless of the type of business. Specifically, the included companies operated in the following sectors: mechanical (3), chemical (2), metallurgical (3), security (1) and manufacturing (1). Starting from the assumption that different roles deal with varying aspects of organisational life, we decided to include different organisational roles from blue-collars to middle-management; in other words, we included professionals from administration, production, commercial, purchasing and human resources departments. A total of 19 focus groups were carried out, with a total of 83 participants (see Table 1).

Table 1. Focus group participants.

\begin{tabular}{ccc}
\hline Variable & Variable Level & Valid Frequency $\%$ \\
\hline \multirow{2}{*}{ Gender } & Male & 50 \\
\cline { 2 - 3 } Age range & Female & 33 \\
\cline { 2 - 3 } & 20-32 years & 24.5 \\
\cline { 2 - 3 } & 33-41 years & 26.6 \\
\hline \multirow{3}{*}{ Professional role } & P2-48 years & 21.2 \\
\cline { 2 - 3 } & Production & 57 \\
\cline { 2 - 3 } & Purchase department & 14 \\
\cline { 2 - 3 } & Human Resources & 12 \\
\cline { 2 - 3 } & Administration & 10 \\
\hline
\end{tabular}

Each focus group was attended from 4 to 6 employees from the same organisation and attendance was voluntary. In fact, the sampling procedure involved a random selection process of potential participants. Once the proposal to participate was received, the person was free to accept or decline, without giving explanations. In the case of refusals, another possible participant was randomly selected until the number established for each group was reached.

\subsection{Measures}

The method of the present study has been characterised by in-depth analyses. We chose to collect data using focus groups for their high and deep information capacity through the debate that is created between the participants under the guidance of a moderator [29].

Focus group drafts provided two main points:

- To map organisational welfare proposals-in order to gather together all the initiatives under macro categories; 
- To explore representations of welfare-in order to understand the meaning (described in terms of the expressed norms, values, beliefs and symbols) associated with the term "organizational welfare".

\subsection{Procedure of Data Collection}

Data was collected via the active participation of organisations in order to understand their experiences and feelings within their organisational environments. In operational terms, focus groups were held at different levels of all the organisations involved. All such groups, lasting 90 min each and audio recorded only after informed consent was obtained, were conducted by members of the research team. We declare that the procedure met the international norms and ethical principles established by the European Union 2016/679 Regulation, the Declaration of Helsinki established by the World Medical Association (1964) and related revisions with written informed consent obtained from each participant.

\subsection{Data Analysis}

We worked with a hierarchical categorisation system combining top-down and bottom-up logic. To categorise the text, using top-down logic we defined 3 macro-categories: namely, welfare proposal mapping, representations related to organisational welfare and process elements of welfare programme implementations.

After this, in order to identify the micro-categories for each of the macro-categories, we analysed the text portions considered with bottom-up logic.

We combined these logics because, based on a literature analysis, we knew these areas needed more detailed studies (top-down logic) and precisely because of these "gaps" we could not establish a priori which specific aspects should be considered for each category (bottom-up logic).

Consequently, we combined two kinds of content analyses. As defined by Hsieh and Shannon [30], we applied the "directed content analysis" (codes are defined before and, eventually, during data analysis) and the "conventional content analysis" (categories and names for categories flow from the data). Additionally, during the top-down phase, the directed content analysis was applied looking for the 3 main macro-categories previously defined. During the bottom-up phase, a conventional content analysis was applied to discover the specific micro-categories. After these two phases, an interpretative process was started to understand the meanings of the macro and micro categories.

Data analysis was conducted by three independent reviewers (the agreement was calculated for each of the under-pairs of judges C.G \& D.G.-C.G. \& C.D.-D.G. \& C.D. and after that the mean value was calculated). Inter-rater reliability was good (Cohen's $\mathrm{K}=87 \%$ ) and was calculated using ComKappa software [31,32]. Cases of disagreement were considered and discussed until a consensus was reached.

Having found a high level of agreement between the data of all the 10 SMEs, the cross-sectional results are outlined below.

\section{Results}

\subsection{Organisational Welfare Proposal Mapping}

A first understanding relates to the abundant range of actions proposed and developed by SMEs, which are possible regardless of economic components.

In fact, we move from those that traditionally fall within the economic benefits (i.e., good petrol, good shopping) - present in all the realities involved - to those of a less 'material nature'.

One of them is physical spaces caretaking that not only concerns the agreeableness and aesthetic but also (mainly) the safety and adequateness of working spaces. It is vital to note that adequacy in terms of safety is one of the most appreciated and safeguarded elements in all the realities involved (this welfare category was identified in 10 out of 10 SMEs). 
"Let's say that if there wasn't that environment, the benefits would do little and nothing. In the sense, yes... they would be a convenience... but it would end there. The environment is fundamental, if you don't have the environment you can't do welfare, because everyone thinks of themselves and ended up there."

Another relevant dimension is the possibility of self-managing one's time (10 out of 10). In particular, the possibility offered by all the organisations in the sample to have a part-time job is greatly valued. Linked to the optimisation topic, there are also all those services finalised to facilitate the conciliation between personal and professional life; namely, all those services present in all the organisations even if in different forms and variations-that fall into the category "work-life balance" that prevent the person from feeling that they "have to compromise" (7 out of 10).

"They listen to us, and they help us... because even when I had my son, I had no one, neither [my] mom nor dad... so I had no one [...]. They helped me with part time, with the schedule I wanted... and it is not 'granted', because they could have said 'no dear, if you are okay so if not that's the gate', also because we're talking of 10 years ago..."

There are then categories that are not immediately linked to daily life in the company but that in terms of impact are not to be considered less important. These categories include all those initiatives linked to physical and psychological health promotion and prevention (4 out of 10), such as free cardiology check or fresh fruit corners. We also found proposals for personal development (i.e., painting classes and vernissage) not only as a professional but as an individual with passions and interests (4 out of 10).

Last but not least, the relationship between the individual and the company; in other words, all those aspects aimed at strengthening the recognition of the value of the person (for example, an employment anniversary dinner gift) and consequently their sense of organisational commitment (3 out of 10 SMEs).

"So, a chance to satisfy in a more adequate way what are the needs today... a way of get[ting] in touch with the territory, from sport, to a cultural need [...] and therefore to feel [that] life is improved for aspects that were not touched [upon] before, therefore to increase well-being... also psychological."

"They are very useful and also make you feel glad. You feel a little, in quotes, pampered."

\subsection{Organisational Welfare Representations}

\subsubsection{Positive Elements}

By conducting an in-depth analysis of representations of these different welfare services, a first understanding relates to the recognition of organisational welfare value that is not necessarily linked to economic components.

When discussing the meaning attributed to the topic of welfare, an emerging and relevant topic is the relational dimension. One of the first highlighted points concerns the importance of perceiving closeness to the entrepreneur figure; so, welfare as proof of a real focus of the company on wanting to safeguard, listen to and understand its employees. Indeed, in order to be able to fulfil its intrinsic nature, welfare should be predisposed to meet the different (and 'real') demands of its recipients.

"Any worker increasingly has to deal with both working and personal time management. Knowing that the company in some way makes [services available] that facilitate you, in my opinion, is just a recognition of the person. You know that you are not just 'a worker'"

Another element that characterises the representation of the worth of welfare concerns welfare as a tool for recognising the value of work. Specifically, people seek a welfare proposition that shows recognition as a symbolic and material "reward" of the professional and their contribution to the company. This implies that the welfare system conveys a message of renewed knowledge and 
recognition toward the worker as a person in their entirety and not as a number or code in a wage. Linked to this aspect is the representation of a worthy welfare; this is the result of a process with several interlocutors that allows professionals to feel involved in organisational life.

Consequently, a necessary premise to guarantee the aforementioned points and the efficacy of welfare proposals is that the choices are a result of a relational process, with discussions and sharing from the different organisational actors.

\subsubsection{Negative Aspects}

The counterpart to these considerations concerns the critical issues that rose for what pertains to the nature of welfare suggestions. A first matter relates to the lack of "welfare awareness and culture" that sometimes characterises professionals working in SMEs. Moreover, communication is not always perceived as clear and effective in highlighting the potential of organisational welfare plans, as well as the benefits and advantages of the suggestions to balance what workers "feel like they're losing".

This is combined with the perception of the scarce possibility of receiving ad hoc plans for the real needs and interests of workers. This concerns not the perception of restrictive options but rather a limited margin of personal discretion in making free choices.

"Even for petrol vouchers, we didn't have a company... what do I know... Shell... we had the distributor near [the company]. For me who [lives] in the area, little changes... but for those who live in the lower Brescia it is problematic... they are forced to [drive] kilometers to fill up... and on Saturdays it is only open until 12, [then on] Saturday afternoon [it] is closed... that is, it is just a way to get around for petrol"

These previous considerations evoke a final one. Thus, when digging into this issue even deeper, the criticisms or doubts that arise toward welfare relate to the need to understand the sense behind the activation of a welfare plan. Without clarity and sharing, welfare can be perceived as a purely economically convenient choice that transcends from a value system.

In this regard, it is crucial to specify that talking about a value system does not imply referencing a position of paternalism or "do-goodism". In fact, when talking about a value system one refers to the organisational choice of investing in human capital in terms of reciprocal growth.

"The sense of belonging, therefore, the quality and also the quantity of work. Unconsciously, you certainly work better. I don't notice it; but I think that all this makes me work better and makes me want to go to work. No, not to go to work... to come here. That's the point."

\subsection{Process of Implementation of Welfare Programmes in SMEs: Elements}

Mapping organisational welfare proposals and exploring the representations connected to them has brought to light the reflections of participants during the focus groups regarding several process elements that allow greater or lesser effectiveness of these initiatives in terms of perception of the care of human resources.

Welfare is deemed to be effective when people perceive it as a choice that goes beyond the value of economic profit. Perceiving that the company awards value to its employees not only from a professional point of view but that it is also attentive in taking care of them to guarantee a good work-life balance; this promotes a sense of duty and responsibility towards one's company regardless of the economic remuneration alone. All this, in terms of process, translates into a fundamental first step: the explanation of the logic and reasons why the organisation is developing welfare initiatives.

"Definitely to promote more employee well-being and then, in my opinion, an employee who feels well is also more encouraged to work well and give all of himself in the job - therefore, you probably also increase the job-you are more attached to the company, you are happier to belong to a company that also looks to your well-being and not (as we said before) only to the technical skills or what you are 
bringing to the company [on] a technical level. Let's say the worker is more enticed and feels more appreciated, therefore, it is definitely a way to consolidate the job."

"It is a sense of mutual responsibility: I am not a number for the company-the company counts for me."

Concurrently with what was just described, as there is no general formula or a pre-defined list of welfare actions that can be adapted to single companies a priori, welfare can become the opportunity for a process of exchange between the company and its employees. In terms of process, this means "keeping professional inside" for the choice of which initiatives to develop/make available.

"At a certain point, you no longer differentiate between... [...] sometimes this is my home too. And I care about it. If I go to the kitchen and see the dirty sink, I am not the cleaning lady, but automatically I clean it... as if it were my home. Because this thing automatically enters you; this is because in all these years they have given you all these attentions and spare parts automatically..."

However, in most realities, even if the involvement of workers is foreseen in a preliminary analysis of needs, this often occurs through questionnaires and surveys and rarely through the activation of discussion and comparison groups.

In terms of process, this element seems to highlight the tendency towards a dual interaction and the loss of an opportunity for circular exchange between professionals.

"I think first of all you should have a good relationship between colleagues, because you work together, you still spend 8 hours a day with them."

"Many are wary... empowering people who must grow up now, they must make decisions motivating their people, getting used to a logic of confrontation, not just a directive of 'Do this, I told you to do so. Move on', or criticism of the neighboring department, instead of comparisons and collaboration. This has always been very difficult, but we are implementing it, it is very slow to achieve but we're working towards it."

Another element that is often lacking in the management of welfare plans concerns the monitoring and assessment of said plans, leaving the perception that (even when present) they are not yet used to their full potential.

"Now we have made some progress you know, but when you asked me what was the most difficult aspect... participation. And then also have your say for fear of saying unimportant things..."

"Trivially... not thinking of giving feedback (even negative) on a service that was actually going badly. If you feel part of the thing and you feel like being an active part, it is natural for you to give constructive feedback; if, on the other hand, you feel the welfare plan is something that has been given to you but you don't know exactly where to put yourself, you'll just receive things and if you like them, good, otherwise you go further."

Combined, these elements comprise the perception of welfare as either formal or substantial. These workers' emphasise, with respect to the importance of certain procedural steps, and clarify how thinking of welfare as a process makes the difference between its perception as a formal choice or as a substantial and effective choice.

"We try to explain to our colleagues, because they are always worried and suspicious, but it is normal that when you change something, people are afraid of change."

"It has emerged that it is very difficult to undo a classic mentality of this area, the result of a strong culture in which workers find it hard to understand and believe in our model which is totally different, participatory." 


\section{Discussion}

An initial yet intriguing element that arose from the data concerned the fact that people-when asked about welfare-in the majority of cases referred to a series of actions that do not necessarily fall into the forms that are conventionally associated with the label of 'organisational welfare'. Thus, among the welfare initiatives reported by workers, we found the more classic ones concerning economic benefits (which for workers seem less interesting and worthy of appreciation), initiatives aimed at improving the quality of physical spaces in organisations, those that support the management of personal time, combining it with working time and finally services and initiatives that promote well-being and personal development. This result can be explained by the fact that in these kinds of organisations the value attributed to welfare is never solely linked to the economic dimension. We can say welfare is deemed to be efficient when professionals perceive that the company is focusing on the promotion of their well-being, in addition to their personal and professional development.

In terms of representation, welfare is what promotes workers' well-being through a process of care and perception of closeness to the entrepreneur/management. The representations and meanings linked with welfare, in fact, refer to processes of identification, participation and co-construction of meaning with respect to the connection of these initiatives with culture and organisational values.

This view of welfare recalls a circular process based on reciprocation (Levinson, 1965), which is a constant process of satisfying expectations and reciprocal relation needs between the individual and the organisation. This activates a complementary dynamic in which the individual and organisation become part of the other due to a significant feeling of identification.

In addition to the concept of identification, another key element is the sharing of responsibility from both parties. It is critical that both company and employees take charge, allowing meaningful and conscious decisions to be made. This means having an open dialogue and exchange of ideas between both parties, where both are willing to question themselves in sharing their respective perspectives. This is also a necessary premise to be able to carry out participatory processes even for what pertains to monitoring and assessment. It is important to remember that these phases imply transparent and clear management on behalf of the organisation, as well as all other players' ability to get involved and take part in a critical monitoring process. This means assuming a proactive position in regard to one's role and to the system as a whole.

For SMEs, this means talking about welfare not as a product but as a process leading us to think about wider organisational processes where elements of participation and circularity are connected to the performance and quality of organisational life.

Clearly, the relational dimension is a necessary premise to all the elements discussed. When welfare is thought out as a shared process that the organisation takes responsibility for, this can become a powerful catalyst to give evidence and strengthen an organisational culture in which the group and the quality of both horizontal and vertical relationships represent a valuable and powerful "tool" to safeguard both the processes and the work. Welfare can then be formed as an opportunity to reflect on whether organisational decisions are reinforcing just the value of the individual or the group as well.

Since talking about welfare as a process refers to meanings related to the quality of life in working contexts, we can understand it as a magnifying glass over organisations' cultural, value and identification dimensions. This allowed us to define 3 possible organisational configurations related to welfare.

"Welfare as a sensible choice" - coherent and efficient welfare (2 out of 10)

Welfare is perceived as an expression of attention towards professionals that contribute to the company's results; thus, in the organisational culture of these companies, human resources are depicted in terms of human capital. Moreover, within such companies, the presence of participatory planning, the attention to the relational side and the choice of transparent communication by management create the premises for the actualisation of widely accepted and well-used welfare plans. In this type of scenario, welfare is not only appreciated but is efficient in terms of its benefits for all parties of the organisation. 
"Welfare with growth potential" - coherent but ineffective welfare (6 out of 10)

In these types of organisational settings, human resources recognise leadership levels in terms of closeness and are attentive to the promotion and safeguarding of well-being. Thus, these realities often come from a history of family management that affectively shaped their DNA. However, because of that the choice of promoting welfare programmes—even if linked to the organisational culture-is not particularly efficient in terms of profit as professionals experience it as a loss of more direct contact with the entrepreneur. Indeed, these kinds of organisations are not yet equipped or prepared with a proper communication strategy and usually lack the implementation of circular exchange processes between professionals.

"Welfare as a poisoned gift"-incoherent and inefficient welfare (2 out of 10)

In these types of organisations, workers perceive the organisational culture to be strongly oriented to profit and not attentive to its human resources. Professionals do not feel acknowledged for their contributions and are not valued in terms of their personal and remunerational growth. For this reason, when companies decide to activate welfare plans, this choice is perceived to be incoherent and "self-serving". Moreover, in these kinds of organisations, there is often a lack of explanation regarding the logic and reasons why the organisation is developing welfare initiatives, in addition to a dearth of needs analysis and participatory processes. Consequently, welfare proposals are not used and, even when they are, they fail to contribute to strengthening the bond and commitment toward the company, sometimes even fostering a sense of frustration.

\section{Conclusions}

As anticipated in the discussion, the challenging part of managing welfare in SMEs is to think about it as a process and not as a product.

Indeed, to think of welfare as a process provides more efficient welfare management in terms of profit, as it allows for the reading and understanding of the structure of factors, dynamics and processes that define the complexity of the quality of life in organisations.

Therefore, with this study, we realised that welfare became a sort of magnifying glass that allowed for the detection of the themes that led the organisations to reflect on their rooted values and identities.

A first finding concerned the fact that SMEs displayed experiences that are far richer than the research and literature revealed on the subject $[1,10,13]$. Every company tended to be carrying out, on a more or less conscious level, some form of welfare. However, in this respect it is worth pointing out that often the most relevant welfare actions are those oriented to promoting relational closeness between the company and its workers, fuelling organisational commitment, and, consequently, promoting the productive and competitive ability of the company itself. Therefore, besides mapping the more "conventional" forms of welfare, one of the first useful guidelines that emerged from this study is that it is important to allow these more implicit dimensions to emerge and have an awareness of them. It is also worth specifying that this does not just imply mapping and highlighting actions, but also understanding the representations related to welfare and the connection with the organisational life in which these actions collocate themselves [2,33-37]. The challenge that arises-especially for SMEs-is to preserve what is known, "familiar" and that gives security, which maintains a stable identity, and acknowledge the urge to change and evolve to respond to new internal and external demands. This implies asking the question of how to value the history and the know-how that was built in time to capitalise and re-define it in a new and innovative way.

This last consideration could also provide an explanation of why the majority of SMEs in the sample fall under the "Welfare with growth potential" profile. Indeed, in these realities, the generational and/or governmental shift is ongoing or is forming and due to be enabled soon, which means they are in a delicate transitional phase between a history of family management-built on a predominantly affective level - to a more managerial and structured one. This could explain why, in these kinds of organisations, welfare proposals are recognised as being coherent with the company values but are not 
particularly efficient in terms of profit as professionals experience them as the loss of more affective and direct contact with the entrepreneur.

We believe that these results have strong implications for management practices, in particular for middle management, who are able to play a key role in engagement and productivity processes through the implementation, management and monitoring of welfare plans [38].

Indeed, middle management without a doubt holds a highly strategic as well as delicate role, collocating itself in a middle ground position with a top-down and bottom-up connection function to promote circularity in the company. In this sense, middle management could be crucial to avoid the risk of falling in the "welfare as a poisoned gift" profile, promoting awareness of the dynamics that characterise the organisation and understanding - in a virtuous circular optic -if the richness of the proposed actions is to be recognised and valued.

In this regard, middle management roles need the legitimisation and the possibility of assuming a connection mandate between the parts. Translated into managerial terms, this means defining to what extent the boundaries between autonomy, delegation and coordination can be permeable in order to allow middle management to reflect on the management of communication, feedback, monitoring and assessment.

When talking about this kind of processes, a fundamental assumption to keep in mind is that it does not only concern the sharing of mere information but of processes of co-creation of shared meaning for which it is necessary to enable participation in light of the responsibility and autonomy of each organisational role. A precious recommendation for leadership roles and middle management is to take care to constantly clarify one's aims and development guidelines, especially with more operating roles. Vice versa, more operating roles should legitimise themselves to clarify their need for feedback or clarification.

In this regard, the group dimension is likely to be one of the most powerful but challenging tools to foster the implementation of welfare plans. In fact, the group dimension can question top management in relation to specific needs, to the promotion of specific actions, to define more clear communication and evaluation processes, and to build and/or negotiate meanings on a horizontal and vertical level. An important remark to make on this concerns the need to think from a systemic and contextual perspective.

On a final reflection, all issues posed and lines of development delineated here should not be considered to be separate from the other; however, it is necessary to identify priorities if not only for the fact that the processes and dynamics involved require time and could imply difficult phases of fatigue and resistance.

Consequently, the dimension of conflict should not be forgotten, as it is also a potential resource if viewed and managed as being an opportunity to create a space and time for discussion to reach a convergence toward a common point.

To conclude, in light of this study, it is possible to state that for SMEs thinking about welfare in terms of process and not in terms of product could create a powerful organisational lever to enable effective welfare implementation and-on a wider view—-the promotion of internal relationships and development.

\section{Limits and Future Studies}

Future studies could investigate these aspects through transversal comparisons between SMEs located in different geographical territories and their business extension (local, nation, international, global). Moreover, it would be interesting [39] deepening the comparison between SMEs with different management models (i.e., family firms or with managerial structures), including SMEs based on agriculture and the provision of services (which very often are even more connoted in family terms).

In light of recent events, it would also be important to explore and understand the impact of Covid-19 in the use of social safety nets (such as welfare) to understand if and how its impact on human resources should be reviewed and rethought. 
Author Contributions: Conceptualization, C.D., D.G. and C.G.; Methodology, C.D., D.G.; Formal Analysis, C.D., D.G.; Investigation, C.D., D.G.; Resources, C.D., D.G.; Writing-Original Draft Preparation, C.D., D.G. and C.G.; Writing-Review \& Editing, C.D., D.G.; Supervision, C.G. All authors have read and agreed to the published version of the manuscript.

Funding: This research has received no external funding.

Acknowledgments: The authors thank Associazione Industriale Bresciana for collaborating in the research.

Conflicts of Interest: The authors report no conflict of interest.

\section{References}

1. Ben-Nasr, H.; Ghouma, H. Employee welfare and stock price crash risk. J. Corp. Financ. 2018, 48, 700-725. [CrossRef]

2. Giorgi, G.; Dubin, D.; Fiz-Perez, J. Perceived Organizational Support for Enhancing Welfare at Work: A Regression Tree Model. Front. Psychol. 2016, 7, 1770. [CrossRef]

3. Galuppo, L.; Gorli, M.; Alexander, B.N.; Scaratti, G. Leading in Social Entrepreneurship: Developing Organizational Resources in Confrontation with Paradoxes. Res. Organ. Chang. Dev. 2019, 27, 167-186. [CrossRef]

4. Schmitz, J.; Schrader, J. Corporate Social Responsibility: A Microeconomic Review of the Literature. J. Econ. Surv. 2013, 29, 27-45. [CrossRef]

5. Di Fabio, A.; Rosen, M.A. Opening the Black Box of Psychological Processes in the Science of Sustainable Development: A New Frontier. Eur. J. Sustain. Dev. Res. 2018, 2, 47. [CrossRef]

6. Huhtala, M.; Kaptein, M.; Feldt, T. How perceived changes in the ethical culture of organizations influence the well-being of managers: A two-year longitudinal study. Eur. J. Work. Organ. Psychol. 2015, 25, 1-18. [CrossRef]

7. Van Der Schaft, A.; Lub, X.; Van Der Heijden, B.I.; Solinger, O. The influence of social interaction on the dynamics of employees' psychological contracting in digitally transforming organizations. Eur. J. Work. Organ. Psychol. 2019, 29, 164-182. [CrossRef]

8. Olivelli, F. L'inquadramento sistematico del welfare aziendale. Riv. Dirit. Sicur. Soc. 2020, 1, 103-124. [CrossRef]

9. Jennings, K.S.; Sinclair, R.R.; Mohr, C.D. Who Benefits from Family Support? Work Schedule and Family Differences. J. Occup. Health Psychol. 2016, 21, 51-64. [CrossRef] [PubMed]

10. Pesenti, L. Il Welfare in Azienda. Imprese «Smart» e Benessere dei Lavoratori; Vita e Pensiero: Milano, Italy, 2016.

11. Caesens, G.; Stinglhamber, F.; Demoulin, S.; De Wilde, M. Perceived organizational support and employees' well-being: The mediating role of organizational dehumanization. Eur. J. Work. Organ. Psychol. 2017, 26, 527-540. [CrossRef]

12. Inekwe, J.N. Financial Distress, Employees' Welfare and Entrepreneurship Among SMEs. Soc. Indic. Res. 2016, 129, 1135-1153. [CrossRef]

13. Wei, Y.; Nan, H.; Wei, G. The impact of employee welfare on innovation performance: Evidence from China's manufacturing corporations. Int. J. Prod. Econ. 2020, 228, 107753. [CrossRef]

14. Coppa, M.; Sriramesh, K. Corporate social responsibility among SMEs in Italy. Public Relat. Rev. 2013, 39, 30-39. [CrossRef]

15. Perrini, F. SMEs and CSR Theory: Evidence and Implications from an Italian Perspective. J. Bus. Ethics 2006, 67, 305-316. [CrossRef]

16. Sarfraz, M.; Qun, W.; Abdullah, M.I.; Alvi, A.T. Employees' Perception of Corporate Social Responsibility Impact on Employee Outcomes: Mediating Role of Organizational Justice for Small and Medium Enterprises (SMEs). Sustainability 2018, 10, 2429. [CrossRef]

17. Longo, M.; Mura, M.; Bonoli, A. Corporate social responsibility and corporate performance: The case of Italian SMEs. Corp. Gov. Int. J. Bus. Soc. 2005, 5, 28-42. [CrossRef]

18. Bonomi, S.; Piccinelli, N.; Rossignoli, C.; Ricciardi, F. Web Platform and Corporate Welfare: An Inclusive Organizational Solution. In From Information to Smart Society; Springer Science and Business Media LLC: Berlin, Germany, 2020; pp. 75-91.

19. Audenaert, M.; Vanderstraeten, A.; Buyens, D. When affective well-being is empowered: The joint role of leader-member exchange and the employment relationship. Int. J. Hum. Resour. Manag. 2016, 28, 2208-2227. [CrossRef] 
20. Acs, Z.J.; Morck, R.; Yeung, B. Entrepreneurship, globalization, and public policy. J. Int. Manag. 2001, 7, 235-251. [CrossRef]

21. Berrone, P.; Cruz, C.; Gomez-Mejia, L.R. Socioemotional Wealth in Family Firms. Fam. Bus. Rev. 2012, 25, 258-279. [CrossRef]

22. Laforet, S. Organizational Culture, Business-To-Business Relationships, and Interfirm Networks; Emerald Group Publishing Limited: Bingley, UK, 2010.

23. Lilius, J.M.; Worline, M.C.; Maitlis, S.; Kanov, J.M.; Dutton, J.E.; Frost, P. The contours and consequences of compassion at work. J. Organ. Behav. 2008, 29, 193-218. [CrossRef]

24. Ripamonti, S.; Scaratti, G. Safety learning, organizational contradictions and the dynamics of safety practice. J. Work. Learn. 2015, 27, 530-560. [CrossRef]

25. Ruggieri, R.A.; Pozzi, M.; Ripamonti, S. Italian Family Business Cultures Involved in the Generational Change. Eur. J. Psychol. 2014, 10, 79-103. [CrossRef]

26. Eisenberger, R.; Stinglhamber, F. Perceived Organizational Support: Fostering Enthusiastic and Productive Employees; American Psychological Association (APA): Washington, DC, USA, 2011.

27. Marta, E.; Marzana, D.; Aresi, G.; Pozzi, M. When living and working well together in organizations changes into good social coexistence: The Talent Club case. World Futures 2016, 72, 1-18. [CrossRef]

28. Ko, S.-H.; Choi, Y. The effects of compassion experienced by SME employees on affective commitment: Double-mediation of authenticity and positive emotion. Manag. Sci. Lett. 2020, 10, 1351-1358. [CrossRef]

29. Morgan, D.L. The Focus Group Guidebook (Focus Group Kit); SAGE Publications: Thousand Oaks, CA, USA, 1998; pp. 29-36.

30. Hsieh, H.-F.; Shannon, S.E. Three Approaches to Qualitative Content Analysis. Qual. Health Res. 2005, 15, 1277-1288. [CrossRef]

31. Cohen, J. A Coefficient of Agreement for Nominal Scales. Educ. Psychol. Meas. 1960, 20, 37-46. [CrossRef]

32. Robinson, B.F.; Bakeman, R. Comkappa: A Windows ' 95 program for calculating kappa and related statistics. Behav. Res. Methods Instrum. Comput. 1998, 30, 731-732. [CrossRef]

33. D'Angelo, C.; Gozzoli, C.; Gazzaroli, D.; Mezzanotte, D. New custodial cultures. Experiences and consequences on prison police's well-being. World Futures 2018, 74, 360-378. [CrossRef]

34. Gozzoli, C. Living and Working Together in Organizations: Theme Relevance-An Introduction. World Futures 2016, 72, 219-221. [CrossRef]

35. Gozzoli, C. Living and Working Together in Organizations: Traces and Ways. World Futures 2016, 72, 1-12. [CrossRef]

36. Gozzoli, C.; Gazzaroli, D.; D'Angelo, C. Who Cares for Those Who Take Care? Risks and Resources of Work in Care Homes. Front. Psychol. 2018, 9, 314. [CrossRef] [PubMed]

37. Spinelli, W.M.; Fernstrom, K.M.; Galos, D.L.; Britt, H.R. Extending Our Understanding of Burnout and Its Associated Factors. Evaluation Health Prof. 2016, 39, 282-298. [CrossRef] [PubMed]

38. Scaratti, G.; Galuppo, L.; Gorli, M.; Gozzoli, C.; Ripamonti, S. The social relevance and social impact of knowledge and knowing. Manag. Learn. 2017, 48, 57-64. [CrossRef]

39. Pozzi, M.; Ripamonti, S.C. Le imprese di famiglia: Una road map psicologica come strumento di lettura delle dinamiche intergenerazionali. Ric. DI Psicol. 2019, 42, 285-311. [CrossRef]

Publisher's Note: MDPI stays neutral with regard to jurisdictional claims in published maps and institutional affiliations.

(C) 2020 by the authors. Licensee MDPI, Basel, Switzerland. This article is an open access article distributed under the terms and conditions of the Creative Commons Attribution (CC BY) license (http://creativecommons.org/licenses/by/4.0/). 